\title{
Evidences of soil warming from long-term trends (1951-2018) in North Rhine-Westphalia, Germany
}

\author{
Kristof Dorau $^{1}$ (D) Chris Bamminger ${ }^{2}$ (D) . Daniel Koch ${ }^{1} \cdot$ Tim Mansfeldt $^{1}$ (D)
}

Received: 22 July 2021 / Accepted: 10 December 2021 / Published online: 15 January 2022

(c) The Author(s) 2022

\begin{abstract}
Soil temperature (ST) is an important property of soils and driver of below ground biogeochemical processes. Global change is responsible that besides variable meteorological conditions, climate-driven shifts in ST are observed throughout the world. In this study, we examined long-term records in ST by a trend decomposition procedure from eleven stations in western Germany starting from earliest in 1951 until 2018. Concomitantly to ST data from multiple depths $(5,10,20,50$, and $100 \mathrm{~cm})$, various meteorological variables were measured and included in the multivariate statistical analysis to explain spatiotemporal trends in soil warming. A significant positive increase in temperature was more pronounced for ST $\left(1.76 \pm 0.59{ }^{\circ} \mathrm{C}\right)$ compared with air temperature (AT; $1.35 \pm 0.35{ }^{\circ} \mathrm{C}$ ) among all study sites. Air temperature was the best explanatory variable to explain trends in soil warming by an average $0.29 \pm 0.21{ }^{\circ} \mathrm{C}$ per decade and the trend peaked during the period from 1991-2000. Especially, the summer months (June to August) contributed most to the soil warming effect, whereby the increase in maximum ST ( $\mathrm{ST}_{\max }$ ) was nearby fivefold with $4.89{ }^{\circ} \mathrm{C}$ compared with an increase of minimum ST $\left(\mathrm{ST}_{\min }\right)$ of $1.02{ }^{\circ} \mathrm{C}$. This widening between $\mathrm{ST}_{\max }$ and $\mathrm{ST}_{\min }$ fostered enhanced diurnal $\mathrm{ST}$ fluctuations at ten out of eleven stations. Subsoil warming up to $+2.3{ }^{\circ} \mathrm{C}$ in $100-\mathrm{cm}$ depth is critical in many ways for ecosystem behavior, e.g., by enhanced mineral weathering or organic carbon decomposition rates. Thus, spatiotemporal patterns of soil warming need to be evaluated by trend decomposition procedures under a changing climate.
\end{abstract}

Keywords Soil temperature $\cdot$ Subsoil warming $\cdot$ Trend analysis

Kristof Dorau

k.dorau@uni-koeln.de

1 Faculty of Mathematics and Natural Sciences, Department of Geosciences, Institute of Geography, University of Cologne, Albertus-Magnus-Platz, 50923 Köln, Germany

2 Environment and Consumer Protection, Department of Soil Protection/Contaminated Sites/Ecotoxicology, North Rhine Westphalian State Agency for Nature, Leibnizstraße 10, 45659 Recklinghausen, Germany 


\section{Introduction}

The spatiotemporal distribution of soil temperature (ST) is inevitable affected by increased air temperature (AT) but in contrast, its trend due to climate change has been less widely propagated. Obviously, one reason is that unlike AT, humans do not feel the direct consequence of a warming soil. However, virtually all biogeochemical processes are directly dependent on the ST and therefore trends are of utmost importance to delineate. For instance, increased ST will enhance (i) metabolic activity of microorganisms, (ii) decomposition of soil organic matter and the supply of released nutrients for plant growth, and (iii) mineral weathering by enhanced feldspar dissolution, among other minerals (Schlesinger and Emily 2013; Williams et al. 2010). All these processes are embedded within a changing climate with either a positive or negative feedback. Air temperatures constantly increased since 1850 and the "period from 1983 to 2012 was likely the warmest 30-year period of the last 1400 years in the Northern Hemisphere" (IPCC 2014). Not surprisingly, a recent study highlighted a substantial increase in surface ST $\left(0.47{ }^{\circ} \mathrm{C} /\right.$ decade; 0-cm depth) and deep ST $\left(0.36{ }^{\circ} \mathrm{C} /\right.$ decade; 40 to $\left.320 \mathrm{~cm}\right)$ in the Tibetan plateau (Fang et al. 2019). In addition to the Tibetan high-altitude region, climate change has also been linked to soil warming in other parts of the world, such as Canada (Qian et al. 2011), the USA (Bradford et al. 2019), and Sweden (Mellander et al. 2007). In order to assess the vulnerability of soil warming under the aspect of climate change, it is desirable to address three important aspects: (i) an altitude gradient should incorporate settings in lower terrain compared with mountainous terrain, (ii) long-term records ( $\geq 30$ years) of ST must integrate a high vertical spatial distribution to differentiate between topsoil and subsoil layers, and (iii) the meteorological data set should include as many as possible parameters.

In most studies, AT is the master variable to explain the variability in ST, although other climate parameters regulate soil temperature as well. For instance, the sunshine duration (SD) shows a general upward trend within the last 40 years in Europe, which agrees well with rising AT in this period (European State of the Climate 2020). Cloudiness degree (CD) acts as an antagonist because the presence of clouds can cut out 70 to $80 \%$ of the incident radiation and has a profound impact too (Saha 2008), whilst being present during the night, the long-wave radiation is reflected and potentially warm up the temperatures on Earth. Soil temperature is influenced by new snow cover (NSC) and seasonal duration of snow cover as well (Sokratov and Barry 2002) and since dry soils heat more easily than wet ones, climate change related impact on precipitation (PP) and evapotranspiration modifies soil moisture and thereupon ST (Weil and Brady 2017).

Overall, ST is a sensitive indicator of climate change and to delineate its trend is of highest importance. The goals of this study were to (i) assess spatiotemporal trends in ST for the federal state North Rhine-Westphalia, (ii) discuss the impact by intrinsic, external, and meteorological variables on soil warming, and (iii) outline the possible consequences of soil warming on biogeochemical processes. To achieve our goals, we employed long-term records of ST ranging from 1951 up to 2018 at high vertical resolution in 5, 10, 20, 50, and 100-cm soil depth and further employed NSC, SD, and CD, besides AT and PP as meteorological parameters. 


\section{Material and methods}

\subsection{Study sites}

The study sites belong to the federal state North Rhine-Westphalia located in western Germany. It encompasses low-altitude plains of the Lower Rhine region up to mountainous terrain of the Central Uplands. A temperate climate prevails and the average AT depends on the altitude between 5 and $11{ }^{\circ} \mathrm{C}$ and a mean precipitation of $920 \mathrm{~mm}$ for the climate period from 1979 to 2008 (LANUV 2010). Criteria to investigate long term trend in ST were (i) a consecutive operation record for 30 years, (ii) no long operational failures with $<5 \%$ missing data, (iii) stations which simultaneously measured meteorological parameters, and finally (iv) comprised a low- to high-altitude gradient (Table 1). From 39 observation stations in the federal district of North RhineWestphalia, eleven of these met the prescribed features. Altitudes ranged from 37 up to $839 \mathrm{~m}$ asl, with spans from 25 up to 60 years of ST data. The monitoring for the study sites Herford and Aachen ended in 2007 and 2010, respectively. The stations are with the exception of Aachen and Münster-Osnabrück in rural areas; thus, a heat-island effect is of minor importance. Maintenance of the stations was done by the German Weather Service.

\subsection{Data collection}

The data was downloaded from a public-available portal hosted by the German Weather Service (DWD Climate Data Center (CDC) 2020). Only the data that has been versioncontrolled and audited by end of the investigation period (December 2018) from the federal agency, e.g., due to changes of the measurement principle, was employed for the trend analysis. Meteorological data included the AT $\left({ }^{\circ} \mathrm{C}\right), \mathrm{SD}(\mathrm{h}), \mathrm{CD}$ (okta), and PP (mm). Soil temperatures were measured in 5,10,20,50, and 100-cm soil depth. Whereas the temperature was conventional measured in the $1950 \mathrm{~s}$, platinum resistance thermometer (PT100) enabled hourly measurements from 1990 onwards, which is true for most of the stations. The raw data comprised $22 \cdot 10^{6}$ observations that were aggregated, when needed, to monthly or yearly averages or sums. All analyses including data manipulation, calculation, and visualization were carried out in Rstudio (version 1.4.1103) (RStudio Team 2021).

\subsection{Trend analysis}

Long-term trends were evaluated by applying the "Seasonal-Trend decomposition procedure based on Loess (STL)" (Cleveland et al. 1990). The STL algorithm enables to decompose a time series into a trend, seasonal and residual component, by using a locally weighted regression (LOESS) technique. The method is robust to outliers so occasional unusual observations have no effect on the trend component. Since the trend in ST was the focus of our study, we utilized a high t.window value, a "periodic" s. window and subsequent default arguments in order to delineate and smoothen the trend. Subsequent to the trend extraction, a linear fit $(f(x)=m x+b)$ was applied on the trend to assess whether the parameter increased or decreased during the course of the investigation period. To determine if the trend is statistically significant, we employed the seasonal adjusted 


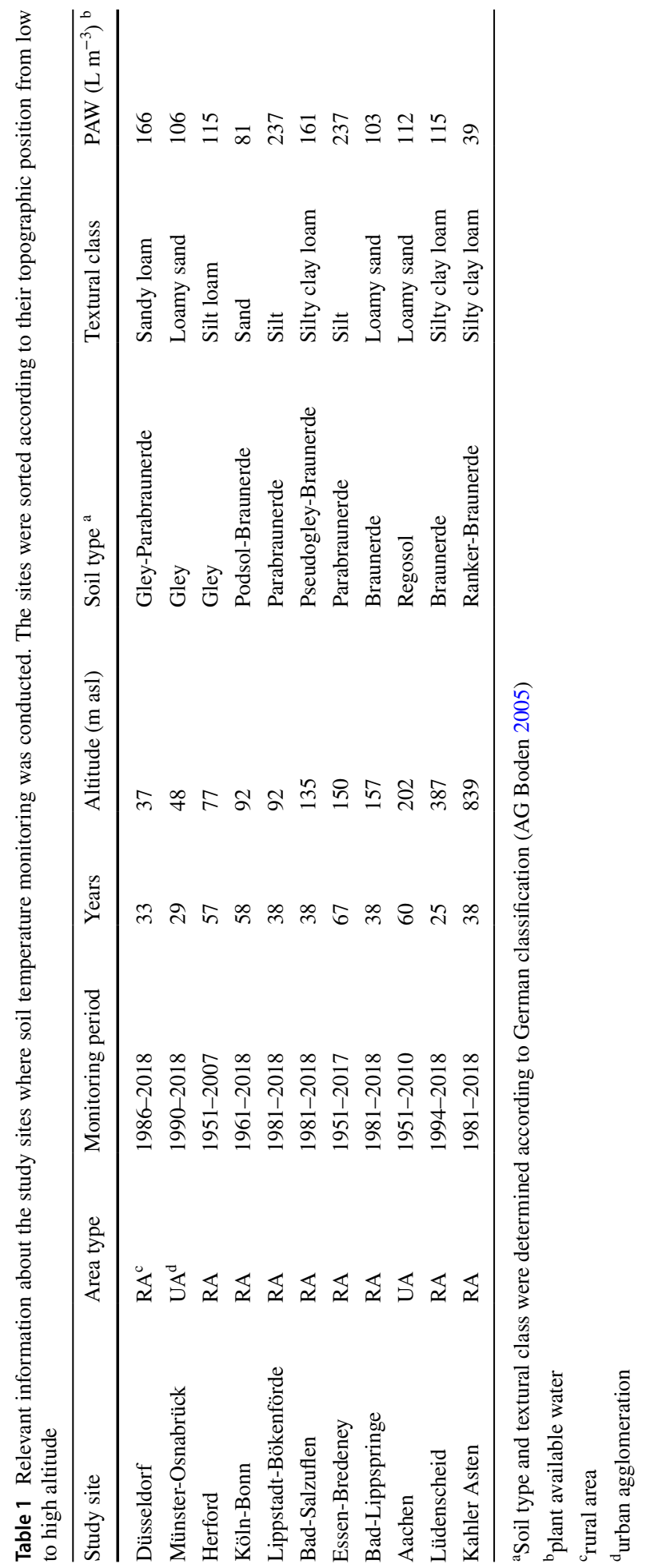


Mann-Kendall trend test, which is a non-parametric test (Hirsch and Slack 1984). Our assumption is that a $p$ value $<0.05$ is statistically significant for the evidence of a trend in the data.

\subsection{Statistical analysis}

RStudio was used to compile the statistical results of the trend analysis (RStudio Team 2021). To reduce the dimensionality of the data set with interrelated variables, we employed a principle component analysis (PCA) using the FactoMineR package. The data was scaled to unit variance prior to the analysis. In addition, testing for differences between ST increase and soil depth, we employed a one-way ANOVA following Tukey's test to compute pairwise differences of the mean. Spearman rank correlation coefficients were calculated and we considered variables being significantly correlated with a $p$ value $<0.05$.

\section{Results and discussion}

\subsection{Spatiotemporal trends of soil warming}

The study sites were equally well distributed along the federal state North Rhine-Westphalia (Fig. 1) and the topography has a striking effect on the mean annual ST (Table 1, Fig. S1B and S1C). For instance, the station Düsseldorf with the lowest altitude featured the highest ST throughout all depths, whereas the site Kahler Asten with the highest altitude featured the lowest ST (Table 1, Fig. 2A). Virtually, among all stations and depths, a statistically significant increase in ST was evident with the only exception for the 5 and 10-cm depth for the study site Herford (Fig. 2A, Fig. S2). Interestingly, the increase was strongest in the 20 -cm depth with $1.87{ }^{\circ} \mathrm{C}$ but this is not significantly different compared with the other depths (Fig. 2B). Thus, soil warming affected the complete soil profile and should not be isolated and portrayed, e.g., with an emphasis on the topsoil. This is different from observations by Subedi and Fullen (2009), who found that soil at 0-cm depth, warmed twice the rate of soil at 100-cm depth between 1982 and 2006. While in our study, the ST increase was on average $1.77{ }^{\circ} \mathrm{C}$, maximum ST $\left(\mathrm{ST}_{\max }\right)$ rose faster with $4.89{ }^{\circ} \mathrm{C}$ increase compared with the minimum ST $\left(\mathrm{ST}_{\min }\right)$ trend of $1.02{ }^{\circ} \mathrm{C}$ (Fig. $2 \mathrm{C}$ ). Even though Wang et al. (2018) explored only surface soil temperatures throughout China, they found the opposing trend that $\mathrm{ST}_{\min }$ rose at a faster pace than $\mathrm{ST}_{\max }$ after 1998. This finding suggests that differences between diurnal ST fluctuations $\left(\Delta \mathrm{ST} ; \mathrm{ST}_{\max }-\mathrm{ST}_{\min }\right)$ decreased but actually none of this pattern was evident in our data. Whereas the $\Delta \mathrm{ST}$ was $4.11 \pm 0.61{ }^{\circ} \mathrm{C}$ from 1951-1960 it rose towards $7.46 \pm 0.88^{\circ} \mathrm{C}$ from $2010-2017$ for the study site EssenBredeney in the 5-cm depth (Fig. 2D). An increase in $\Delta$ ST was evident among all stations, with the exception of the site Herford (Fig. S3). Obviously, enhanced diurnal fluctuations not only control water transport during day-night cycles but also have implications for various ecological processes. On a seasonal basis, the summer season from June to August of each year contributed most to an increase in ST and the last decade from 2010-2018 deviated most from the long-term average. Enhancement of soil warming during the summer season was also found for stations in Ireland (García-Suárez and Butler 2006) and Iran (Araghi et al. 2017). However, the setting is important since continental cool sites exhibited the largest warming during the spring months and settings featuring a melting season e.g., the Icelandic highlands, and warming was found throughout all seasons except 


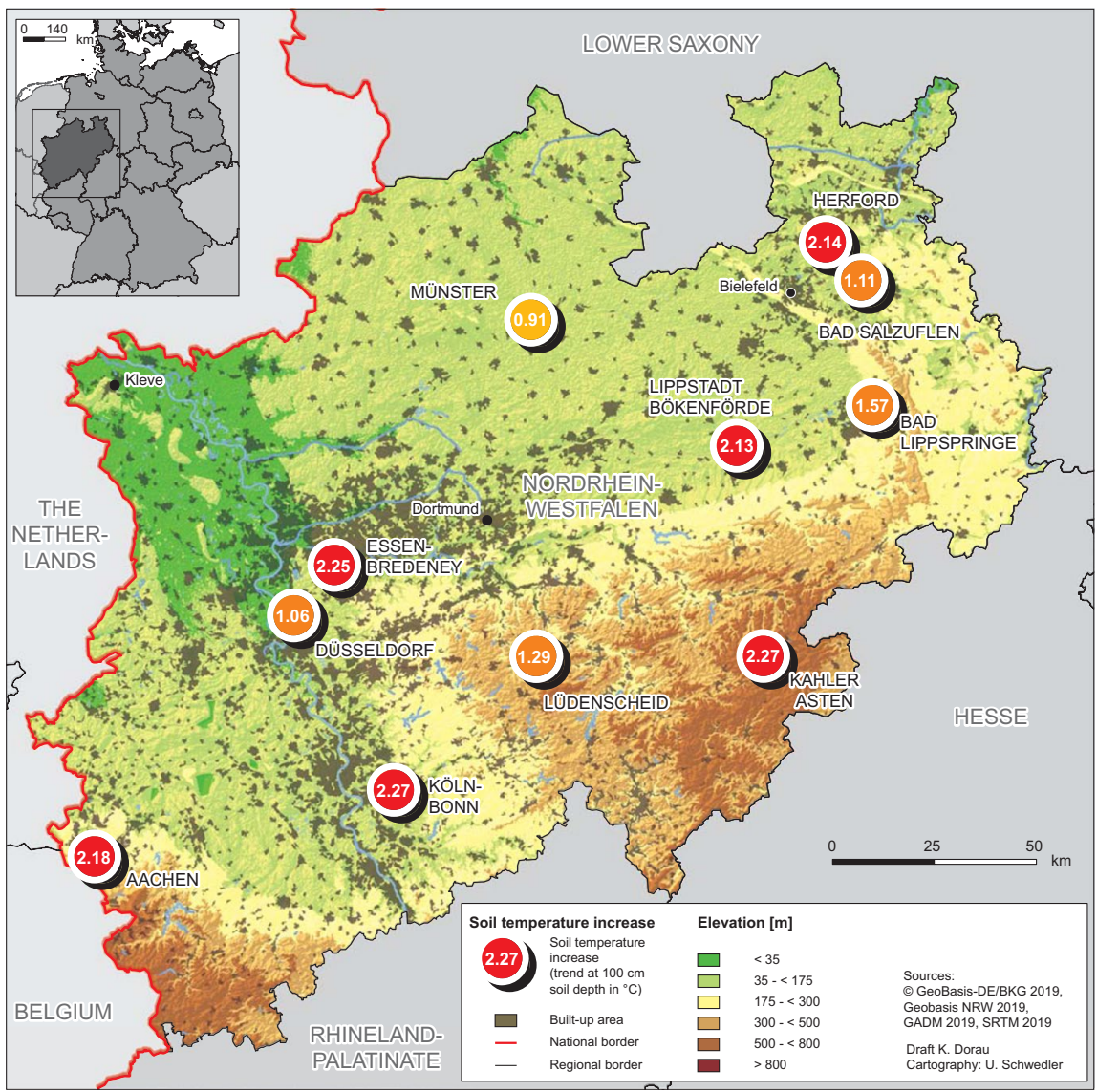

Fig. 1 Location of the study sites in North Rhine-Westphalia with temperature increase in 100-cm soil depth

the spring season from May to June (Petersen 2021). Among all study sites in the present study, the increase accelerated from 1985 onwards experiencing a shift towards higher ST, respectively (Fig. 2C). The decadal increase in ST was strongest from 1990-2000 with $0.56 \pm 0.28{ }^{\circ} \mathrm{C}$ (Fig. 3A) but the long-term increase with $0.29 \pm 0.21{ }^{\circ} \mathrm{C}$ per decade is below the values reported in literature from other regions of the northern Hemisphere (Fig. 3B).

\subsection{Influencing factors on soil warming}

Air temperatures significantly increased among all stations (Fig. 4B) and AT was the best explanatory variable to decipher trends in soil warming (Fig. 5A and B). However, the strongest increase in AT did not necessarily match with the strongest increase in ST (Fig. 5C), which highlights the multifactorial complexity of soil warming. Especially, snow depth and seasonal duration of snow depth are important factors (Chudinova et al. 2006). We verified a decrease in new snow depth at two out of eleven stations (Fig. 4D) 

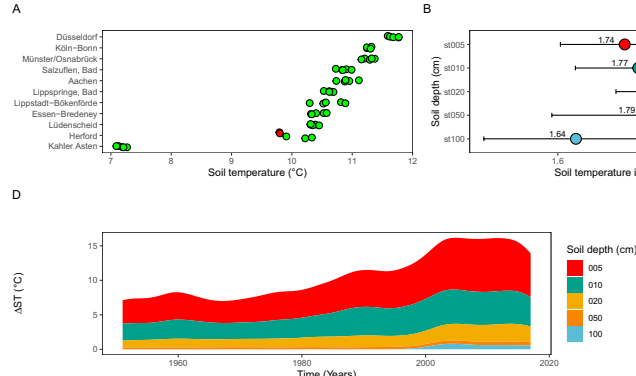
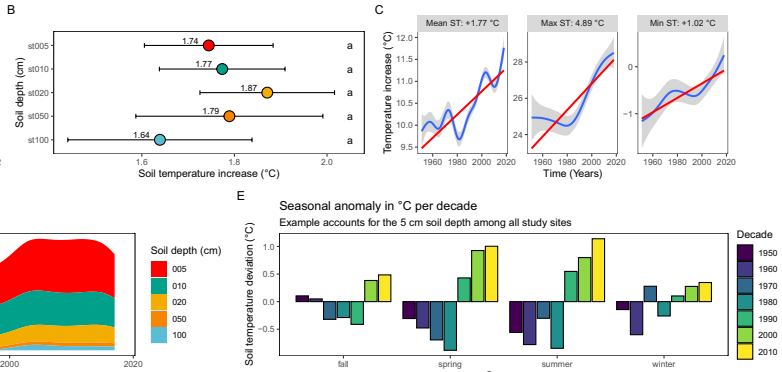

Fig. 2 A Summary statistics of soil temperature (ST) trends with the mean ST across the study sites with green colors indicating a statistically significant $(p<0.05)$ increasing and red colors indicating no trend according to the seasonal adjusted Mann-Kendall test. The depth-specific increase in ST as mean and standard error of the mean among all study sites is shown in $\mathbf{B}$. Panel $\mathbf{C}$ shows the decomposed trend line among all stations and depths (blue line) with the 95\% confidence level (grey band) and the linear model (red line) differentiated for the average, maximum, and minimum ST. D The stronger increase in maximum ST than minimum ST favored an increase in $\Delta \mathrm{ST}$ over time (daily $\mathrm{ST}_{\max }-$ daily $\mathrm{ST}_{\min }$ ) visualized as stacked area chart for the study site Essen-Bredeney. E Finally, seasonal anomalies from the long-term average are colorized by decadal groups starting from 1950

A

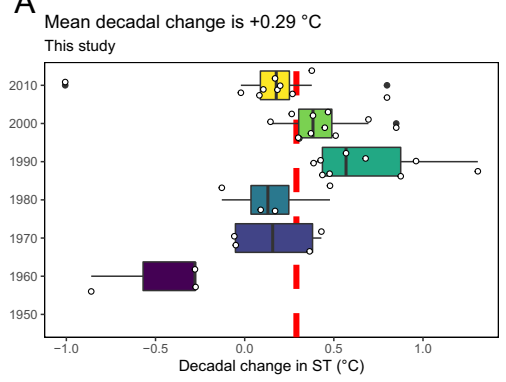

B

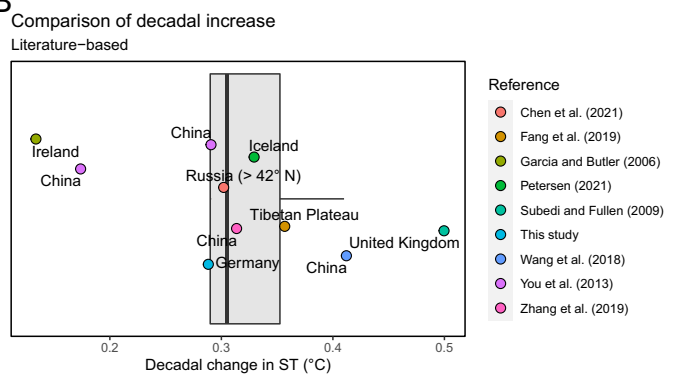

Fig. 3 Mean decadal change in soil temperature within this study (A) and comparison with literature-based data (B). Please note the different scaling of the $x$-axes. Sources: Chen et al. 2021; Fang et al. 2019; GarcíaSuárez and Butler 2006; Guangyong et al. 2013; Petersen 2021; Subedi and Fullen 2009; Wang et al. 2018; Zhang et al. 2019
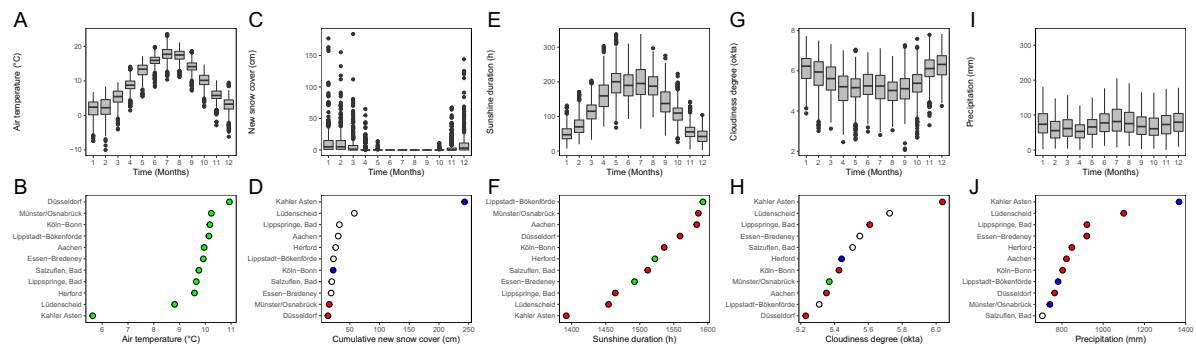

Fig. 4 Summary statistics of meteorological variables on a monthly basis among all study sites and for the overall mean for air temperature $(\mathbf{A}$ and $\mathbf{B})$, new snow cover $(\mathbf{C}$ and $\mathbf{D})$, sunshine duration $(\mathbf{E}$ and $\mathbf{F})$, cloudiness degree ( $\mathbf{G}$ and $\mathbf{H}$ ), and precipitation (I and $\mathbf{J})$. Green colors indicate a statistically significant $(p<0.05)$ increasing trend over time, blue colors a decreasing trend, and red colors indicate no trend according to the seasonal adjusted Mann-Kendall test $(\mathbf{B}, \mathbf{D}, \mathbf{F}, \mathbf{H}, \mathbf{J})$. Hollow circles indicate $>5 \%$ of missing data for a particular variable and, thus, this data was not further evaluated 

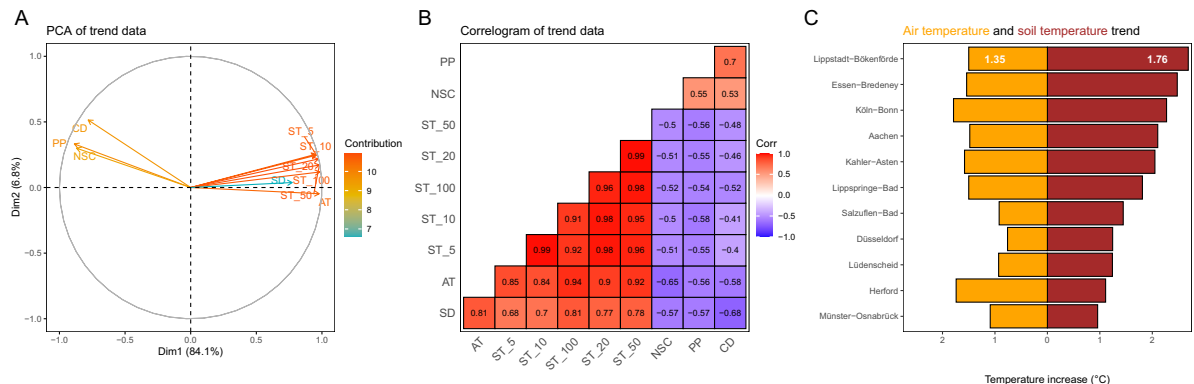

Fig. 5 Principal component analysis (PCA) of trend data from the study sites under investigation (A), a correlogram with the spearman correlation coefficients $(\mathbf{B})$, and a pyramid chart that integrates air and the averaged soil temperature trend sorted by decreasing soil temperature $(\mathbf{C})$

whereby the months from May to October were virtually snow-free across the federal state (Fig. 4C). An early snow melt at the site Kahler Asten rendered the month April snow-free at present contrary to the early decades from 1980 to 1990 (Fig. S5I) and, thus, a shortening of the snow season is certainly a warming agent by increased solar absorption (Lawrence and Slater 2010). High-altitude sites such as Kahler Asten are particularly vulnerable to contribute to an overall trend in soil warming in the future, since snow cover alters the energy budget of a soil due to its low thermal conductivity and high albedo (Zhang et al. 2008). In addition, the relationship between SD and CD is strong (Fig. 5A and B) and generally shows a codependence (Matuszko 2012). This is true on a daily basis but on the long-term, only the station Herford showed evidence that an increased trend in SD goes along with a concomitant decrease in $\mathrm{CD}$ (Fig. $4 \mathrm{~F}$ and $\mathrm{H}$ ). Even though only a few stations revealed a significant trend in SD and CD for the federal state North Rhine-Westphalia at present, anomalies in cloudiness and record high sunshine hours derived by satellite observations since 1980s were evident for Europe (European State of the Climate 2020) and will likely contribute towards accelerated soil warming in conjunction with the rising AT. Despite the rising AT, careful consideration must be addressed to soil moisture feedback mechanisms (Zhang et al. 2001), which were the main reason that summer ST decreased by up to $4{ }^{\circ} \mathrm{C}$ due to changes in rainfall at Irkutsk under special circumstances (Zhang et al. 2001). Our findings that ST showed a stronger increase than AT (Fig. 5C) and that the summer season contributed most to the increase in soil warming (Fig. 2E) match with findings from a study in Ireland (García-Suárez and Butler 2006). They formulated that increased ST is not only a result of warming but also of drier conditions in summer. In our study, three out of eleven stations revealed a decrease in PP (Fig. 4J) that was most pronounced at the site Kahler Asten with a decrease of $>30 \mathrm{~mm}$ (Fig. S5E). Drier soils are more easily heated than wet soils due to changes in the heating capacity and if the soil is not affected by capillary rise from shallow groundwater - which is the case for Düsseldorf, MünsterOsnabrück, and Herford (Table 1) — these settings receive their soil moisture exclusively by PP. If a study site becomes drier, e.g., due to shifts in PP and/or increased evapotranspiration rates, the heat transfer is strongly affected. The soil texture modifies this behavior, which is a sandy substrate at Herford up to more fine-textured soils, e.g., at Kahler Asten (Table 1). However, we cannot disentangle any trends due to differences in soil texture from the given data set. Overall, the influence of meteorological variables on trends in ST decreased by $\mathrm{AT}<\mathrm{PP}<\mathrm{NSC}<\mathrm{CD}<\mathrm{SD}$ as indicated by the PCA, from which about $90 \%$ of variation in the data could be explained by PC1 and PC2 (Fig. 5A). Even if intrinsic and 
meteorological factors are incorporated in the evaluation of soil warming, external factors such as soil management, e.g., tillage systems, crop rotation, clear cutting, have a direct impact on the thermal properties of a soil and consequently on the response of soil warming in the future (Table 2).

\subsection{Subsoil warming and implications for biogeochemical processes}

Subsoil harbor an important reservoir of soil organic carbon (SOC) with turnover times of centuries to millennia. In this context, it is even more serious that subsoil warming alters the stability of SOC and enhances decomposition rates due to associated shifts in the functional gene structure of microbial communities, as recently shown by artificial subsoil warming of $\sim 2{ }^{\circ} \mathrm{C}$ in 25 -cm depth over a 10-year period (Cheng et al. 2017). Obviously, soil warming not only accelerates the decomposition of old SOC pools in subsoil but also highlights the vulnerability of years-to-decades old SOC in topsoil, which accounts for the largest fraction of total SOC in terrestrial soils globally (Hopkins et al. 2012). We found a strong evidence of subsoil warming $>2{ }^{\circ} \mathrm{C}$ in $100-\mathrm{cm}$ soil depth at six out of eleven stations throughout the study area (Fig. 1). This is also reflected by an increase of phenological days $>5^{\circ} \mathrm{C}$ by 25 days in 100-cm soil depth on average (Fig. S4E), which would potentially increase biomass production. Soil warming not only influences the persistence of SOC as an ecosystem property (Schmidt et al. 2011), it contributes significantly to mineral weathering and ecosystem nutrition in general. In 2019, up to $25 \%$ of the land use in North Rhine-Westphalia constitutes forest and $47 \%$ is used agriculturally (LANUV 2021). The productivity of forest ecosystems is reliant by efficient reutilization of organic-bound nutrients derived from litterfall, but it was highlighted recently that nutrient uptake from saprolite weathering constitutes an important geogenic nutrient pathway as well (Uhlig et al. 2020). Links to soil warming can also be established to mineral weathering by an alteration of mineral reactivity and nutrient availability (Doetterl et al. 2018). Soil temperature was reported to be the main driver of silicate weathering rates compared with $p \mathrm{CO}_{2}$ levels and organic acids (Brady and Carroll 1994; Gwiazda and Broecker 1994). Projected future increases in ST up to $5{ }^{\circ} \mathrm{C}$ for the period from 2070 to 2099 in forested sites of Quebec can be seen as a harbinger of what we have to expect with the associated impacts on biogeochemical cycles (Houle et al. 2012). The linkage between subsoil warming and some of the before mentioned biogeochemical processes can certainly be transferred to other regions on the world and is not specifically tailored for the study site under investigation.

\section{Conclusions}

Long-term ST trend data in North Rhine-Westphalia revealed a significant increase with an average $0.29 \pm 0.21{ }^{\circ} \mathrm{C}$ per decade. Thereby, we identified important aspects that cover the following: First, soil warming affected the whole soil profile among the study sites. Second, soil warming in the summer months contributed most to the overall soil warming effect and trends in $\mathrm{ST}_{\max }$ values exceeded $\mathrm{ST}_{\min }$ values. Third, thereupon $\Delta \mathrm{ST}\left(\mathrm{ST}_{\max }-\mathrm{ST}_{\min }\right)$ rose across ten of eleven sites until now and this highlights that shifts in the thermal regime of the soils are taking place at rapid pace, e.g., intensification of diurnal temperature cycles. Finally, subsoil warming in $100-\mathrm{cm}$ depth up to $2.3{ }^{\circ} \mathrm{C}$ is an important observation and needs to be included with emphasis on biogeochemical processes that cover soil organic carbon dynamics and mineral weathering rates modifying the nutrition supply for plants. A 


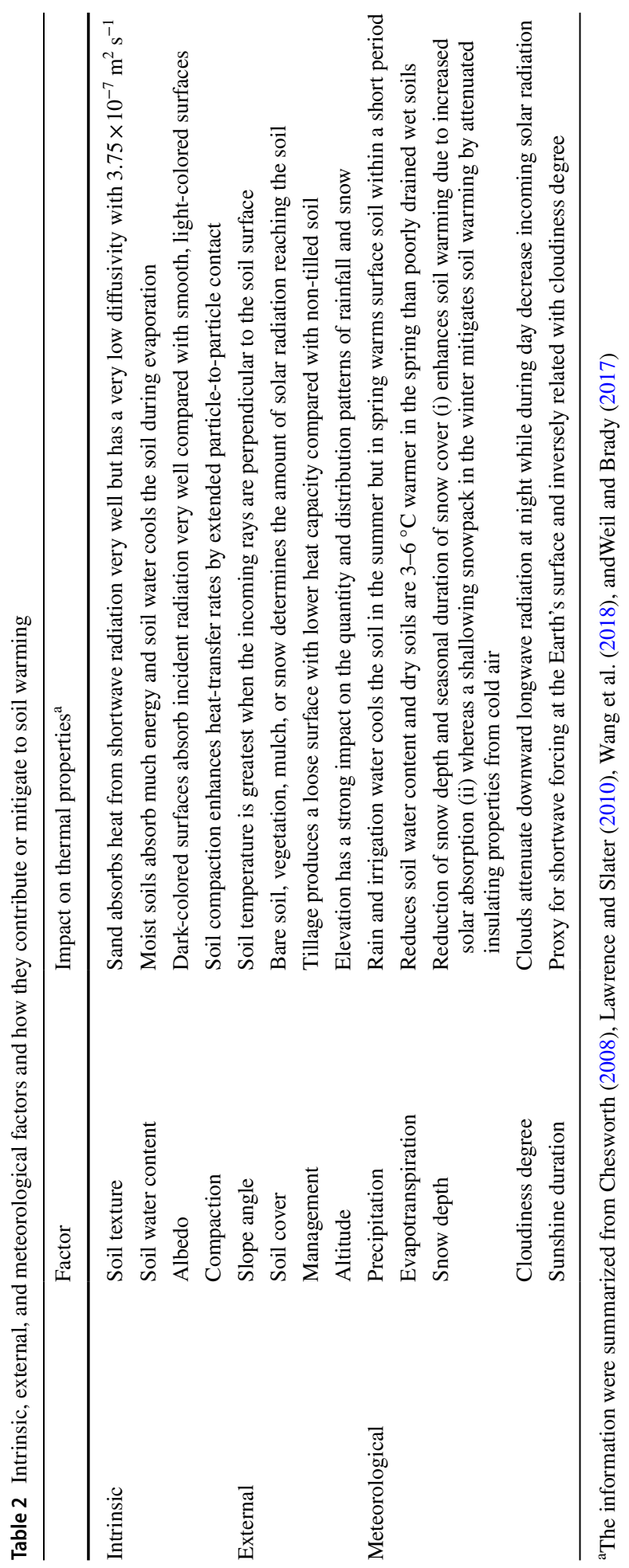


successive extension of phenological days with temperatures $>5^{\circ} \mathrm{C}$ by 25 days could have a significant impact on forested and agricultural used ecosystems. To decipher trends in soil warming temporally and spatially is important as a metric and should be linked to not only meteorological-dependent climate change observations.

Supplementary Information The online version contains supplementary material available at https://doi. org/10.1007/s10584-021-03293-9.

Acknowledgements We greatly acknowledge the support by Miss Ulrike Schwedler for creating the study site map.

Funding Open Access funding enabled and organized by Projekt DEAL.

Data availability All data can be downloaded from a public-available portal hosted by the German Weather Service (https://cdc.dwd.de/portal/).

Materials availability Not applicable.

Code availability The $\mathrm{R}$ script will be made available upon request from the corresponding author.

\section{Declarations}

Competing interests The authors declare no competing interests.

Open Access This article is licensed under a Creative Commons Attribution 4.0 International License, which permits use, sharing, adaptation, distribution and reproduction in any medium or format, as long as you give appropriate credit to the original author(s) and the source, provide a link to the Creative Commons licence, and indicate if changes were made. The images or other third party material in this article are included in the article's Creative Commons licence, unless indicated otherwise in a credit line to the material. If material is not included in the article's Creative Commons licence and your intended use is not permitted by statutory regulation or exceeds the permitted use, you will need to obtain permission directly from the copyright holder. To view a copy of this licence, visit http://creativecommons.org/licenses/by/4.0/.

\section{References}

Boden AG (2005) Bodenkundliche Kartieranleitung, 5th edn. Schweizerbart science publishers, Stuttgart, Germany

Araghi A, Mousavi-Baygi M, Adamowski J (2017) Detecting soil temperature trends in Northeast Iran from 1993 to 2016. Soil Till Res 174:177-192. https://doi.org/10.1016/j.still.2017.07.010

Bradford JB, Schlaepfer DR, Lauenroth WK, Palmquist KA, Chambers JC, Maestas JD, Campbell SB (2019) Climate-driven shifts in soil temperature and moisture regimes suggest opportunities to enhance assessments of dryland resilience and resistance. Front Ecol Evol 7:1-16. https://doi.org/10. 3389/fevo.2019.00358

Brady PV, Carroll SA (1994) Direct effects of $\mathrm{CO}_{2}$ and temperature on silicate weathering: possible implications for climate control. Geochim Cosmochim Acta 58:1853-1856. https://doi.org/10.1016/00167037(94)90543-6

Chen L, Aalto J, Luoto M (2021) Significant shallow-depth soil warming over Russia during the past 40 years. Global Planet Change 197:103394. https://doi.org/10.1016/j.gloplacha.2020.103394

Cheng L, Zhang N, Yuan M, Xiao J, Qin Y, Deng Y, Tu Q, Xue K, Van Nostrand JD, Wu L, He Z, Zhou X, Leigh MB, Konstantinidis KT, Schuur EAG, Luo Y, Tiedje JM, Zhou J (2017) Warming enhances old organic carbon decomposition through altering functional microbial communities. ISME J 11:18251835. https://doi.org/10.1038/ismej.2017.48

Chesworth W (2008) Encyclopedia of soil science. Springer, Dordrecht, The Netherlands 
Chudinova SM, Frauenfeld OW, Barry RG, Zhang T, Sorokovikov VA (2006) Relationship between air and soil temperature trends and periodicities in the permafrost regions of Russia. J Geophys Res-Earth 111:1-15. https://doi.org/10.1029/2005JF000342

Cleveland R, Cleveland W, McRae J, Terpenning I (1990) STL: a seasonal-trend decomposition procedure based on loess. J Off Stat 6:3-73

CWD Climate Data Center (CDC) (2020) Stündliche Stationsmessungen der Erdbodentemperatur in $5 \mathrm{~cm}$ Tiefe in ${ }^{\circ} \mathrm{C}$ für Deutschland, Version v19.3. Accessed 03 November 2020.

Doetterl S, Berhe AA, Arnold C, Bodé S, Fiener P, Finke P, Fuchslueger L, Griepentrog M, Harden JW, Nadeu E, Schnecker J, Six J, Trumbore S, Van Oost K, Vogel C, Boeckx P (2018) Links among warming, carbon and microbial dynamics mediated by soil mineral weathering. Nat Geosci 11:589-593. https://doi.org/10.1038/s41561-018-0168-7

European State of the Climate (2020) Copernicus climate change service, full report: climate.copernicus.eu/ ESOTC/2020. Accessed July 20 2021. Copernicus Climate Change Service (C3S).

Fang X, Luo S, Lyu S (2019) Observed soil temperature trends associated with climate change in the Tibetan Plateau, 1960-2014. Theor Appl Climatol 135:169-181. https://doi.org/10.1029/2010JD0150 12

García-Suárez AM, Butler CJ (2006) Soil temperatures at Armagh Observatory, Northern Ireland, from 1904 to 2002. Int J Climatol 26:1075-1089. https://doi.org/10.1002/joc.1294

Guangyong YOU, Yiping Z, Schaefer D, Liqing SHA, Yuhong LIU, Hede G, Zhenghong TAN, Zhiyun LU, Chuansheng WU, Youneng XIE (2013) Observed air/soil temperature trends in open land and understory of a subtropical mountain forest, SW China. Int J Climatol 33:1308-1316. https://doi.org/ 10.1002/joc. 3494

Gwiazda RH, Broecker WS (1994) The separate and combined effects of temperature, soil $\mathrm{pCO}_{2}$, and organic acidity on silicate weathering in the soil environment: formulation of a model and results. Global Biogeochem Cy 8:141-155. https://doi.org/10.1029/94GB00491

Hirsch RM, Slack JR (1984) A nonparametric trend test for seasonal data with serial dependence. Water Resour Res 20:727-732. https://doi.org/10.1029/WR020i006p00727

Hopkins FM, Torn MS, Trumbore SE (2012) Warming accelerates decomposition of decades-old carbon in forest soils. Proc Natl Acad Sci 109:E1753-E1761. https://doi.org/10.1073/pnas.1120603109

Houle D, Bouffard A, Duchesne L, Logan T, Harvey R (2012) Projections of future soil temperature and water content for three southern Quebec forested sites. J Climate 25:7690-7701. https://doi.org/10. 1175/JCLI-D-11-00440.1

IPCC (2014) IPCC, 2014: Climate change 2014: synthesis report. Contribution of Working Groups I, II and III to the Fifth Assessment Report of the Intergovernmental Panel on Climate Change [Core Writing Team, R.K. Pachauri and L.A. Meyer (eds.)]. IPCC, Geneva, Switzerland.

LANUV (2010) LANUV-Fachbericht 27: Klima und Klimawandel in Nordrhein-Westfalen, Daten und Hintergründe. https://www.lanuv.nrw.de/fileadmin/lanuvpubl/3_fachberichte/30027.pdf. Accessed July 202021.

LANUV (2021) Flächenentwicklung in Nordrhein-Westfalen - Berichtsjahre 2017-2019. https://www. flaechenportal.nrw.de/fileadmin/user_upload/20210301_LANUV_Bericht_zur_Flaechenentwicklung_ 2017_-_2019.pdf. Accessed July 202021.

Lawrence DM, Slater AG (2010) The contribution of snow condition trends to future ground climate. Clim Dyn 34:969-981. https://doi.org/10.1007/s00382-009-0537-4

Matuszko D (2012) Influence of cloudiness on sunshine duration. Int J Climatol 32:1527-1536. https://doi. org/10.1002/joc. 2370

Mellander P-E, Löfvenius MO, Laudon H (2007) Climate change impact on snow and soil temperature in boreal Scots pine stands. Clim Change 85:179-193. https://doi.org/10.1007/s10584-007-9254-3

Petersen GN (2021) Trends in soil temperature in the Icelandic highlands from 1977 to 2019. Int J Climatol n/a. https://doi.org/10.1002/joc.7366

Qian B, Gregorich EG, Gameda S, Hopkins DW, Wang XL (2011) Observed soil temperature trends associated with climate change in Canada. J Geophys Res 116:1-16. https://doi.org/10.1029/2010JD015012

RStudio Team (2021) RStudio: integrated development environment for R. RStudio, PBC, Boston, MA.

Saha K (2008) The Earth's atmosphere. Springer, Heidelberg, Germany

Schlesinger WH, Emily SB (2013) Biogeochemistry: an analysis of global change, 3rd edn. Academic Press, Amsterdam, Netherlands

Schmidt MWI, Torn MS, Abiven S, Dittmar T, Guggenberger G, Janssens IA, Kleber M, Kogel-Knabner I, Lehmann J, Manning DAC, Nannipieri P, Rasse DP, Weiner S, Trumbore SE (2011) Persistence of soil organic matter as an ecosystem property. Nature 478:49-56. https://doi.org/10.1038/nature10386

Sokratov SA, Barry RG (2002) Intraseasonal variation in the thermoinsulation effect of snow cover on soil temperatures and energy balance. J Geophys Res 107:1-6. https://doi.org/10.1029/2001JD000489 
Subedi M, Fullen MA (2009) Temporal changes in soil temperature at the Hilton Experimental Site, Shropshire, UK (1982-2006): evidence of a warming trend? Arch Agron Soil Sci 55:105-113. https://doi. org/10.1080/03650340802343159

Uhlig D, Amelung W, von Blanckenburg F (2020) Mineral nutrients sourced in deep regolith sustain longterm nutrition of mountainous temperate forest ecosystems. Global Biogeochem Cy 34:1-21. https:// doi.org/10.1029/2019GB006513

Wang L, Henderson M, Liu B, Shen X, Chen X, Lian L, Zhou D (2018) Maximum and minimum soil surface temperature trends over China, 1965-2014. J Geophys Res 123:2004. https://doi.org/10.1002/ 2017JD027283

Weil RR, Brady NC (2017) The nature and properties of soils, 15th edn. Pearson, Essex, England.

Williams JZ, Bandstra JZ, Pollard D, Brantley SL (2010) The temperature dependence of feldspar dissolution determined using a coupled weathering-climate model for Holocene-aged loess soils. Geoderma 156:11-19. https://doi.org/10.1016/j.geoderma.2009.12.029

Zhang H, Liu B, Zhou D, Wu Z, Wang T (2019) Asymmetric soil warming under global climate change. Int J Env Res Pub He 16:1504. https://doi.org/10.3390/ijerph16091504

Zhang T, Barry RG, Gilichinsky D, Bykhovets SS, Sorokovikov VA, Ye J (2001) An amplified signal of climatic change in soil temperatures during the last century at Irkutsk, Russia. Clim Change 49:41-76. https://doi.org/10.1023/A:1010790203146

Zhang Y, Wang S, Barr AG, Black TA (2008) Impact of snow cover on soil temperature and its simulation in a boreal aspen forest. Cold Reg Sci Technol 52:355-370. https://doi.org/10.1016/j.coldregions.2007. 07.001

Publisher's Note Springer Nature remains neutral with regard to jurisdictional claims in published maps and institutional affiliations. 